\title{
Misallocation and Manufacturing TFP in Korea, 1982-2007
}

\author{
Minho Kim, Jiyoon Oh, and Yongseok Shin
}

\begin{abstract}
The authors apply the analysis of Hsieh and Klenow (2009) to assess the degree of resource misallocation in the Republic of Korea manufacturing sector from 1982 to 2007. They find improvement in the aggregate allocative efficiency during the first decade and a strong reversal after 1992. This pattern reflects the dynamics of the within-industry distortion measures for most industries and is consistent with the evolving systematic relationship between the age/value added of establishments and their measured idiosyncratic distortions over the sample period. Their finding suggests that the observed dispersion in revenue productivity should not be dismissed as mere artifacts of misspecification or measurement errors. (JEL D24, L11, L60, O47)
\end{abstract}

Federal Reserve Bank of St. Louis Review, Second Quarter 2017, 99(2), pp. 233-44. https://doi.org/10.20955/r.2017.233-244

\footnotetext{
Minho Kim and Jiyoon Oh are associate fellows at the Korea Development Institute. Yongseok Shin is an associate professor of economics at Washington University in St. Louis. The authors thank the editor and an anonymous referee for many helpful comments.

(C) 2017, Federal Reserve Bank of St. Louis. The views expressed in this article are those of the author(s) and do not necessarily reflect the views of the Korea Development Institute, the Federal Reserve System, the Board of Governors, or the regional Federal Reserve Banks. Articles may be reprinted, reproduced, published, distributed, displayed, and transmitted in their entirety if copyright notice, author name(s), and full citation are included. Abstracts, synopses, and other derivative works may be made only with prior written permission of the Federal Reserve Bank of St. Louis.
} 
While this idea is not new, it was Hsieh and Klenow (2009), using detailed plant-level data on the Chinese and the Indian manufacturing sectors, who first estimated the quantitative importance of the within-country allocative efficiency on aggregate TFP. The starting point is that an efficient allocation dictates the equalization of marginal products of production factors across production units. For example, if we have two plants with different marginal products of capital, the total output and, hence, measured productivity can be raised at no cost by shifting one unit of capital from the low-marginal-product plant to the high-marginalproduct plant. In the data, Hsieh and Klenow (2009) estimated a huge dispersion of marginal products across plants, even within a narrowly defined industry. They conclude that, if the resource misallocation in China and India were reduced (i.e., the dispersion in marginal products were reduced by reallocating resources from low-marginal-product plants to highmarginal-product plants) to the level in the U.S. manufacturing sector, their manufacturing TFP would rise by as much as 50 percent and 60 percent, respectively.

In this article, we apply Hsieh and Klenow's (2009) method to the microdata on the Republic of Korea (hereafter Korea) manufacturing sector to study the evolution of allocative efficiency over a quarter century (1982-2007). While this methodology has been applied to the microdata of various countries, few countries have high-quality microdata spanning enough years to allow for the analysis of medium-run dynamics of allocative efficiency. Korea is one of the exceptions, and we use restricted-access repeated cross-sectional data for our analysis.

Across the entire sample period, we find a high degree of resource misallocation in the Korean manufacturing sector, although it is smaller than the misallocation in China and India reported by Hsieh and Klenow (2009). We also find that the age and overproduction (i.e., production in excess of the efficient benchmark) of establishments are strongly positively correlated, while their size (measured by value added) is negatively correlated with overproduction. In other words, young and large establishments tend to produce too little-that is, they have higher marginal products than the respective industry average. This overall pattern reflects the within-industry patterns at the two-digit level.

Using the time dimension of the data, we find that the allocative efficiency in the Korean manufacturing sector improved from 1982 to 1991 but then reversed its course and deteriorated significantly after 1992 . We find that this non-monotonic aggregate dynamic reflects the common trend in within-industry allocative efficiency. Later we discuss how this pattern may be explained by the large-scale policy changes of 1982 and 1993.

As discussed later, Hsieh and Klenow's (2009) method is based on strong simplifying assumptions, and the estimates may not accurately reflect the degree of misallocation in reality. We think of their simple, transparent method as a first-pass diagnostic of allocative efficiency. We then briefly discuss whether the results of this diagnostic test correlate with known changes in policies and market conditions over time.

\section{METHODOLOGY}

Hsieh and Klenow (2009) study whether capital and labor are allocated efficiently among plants with differing productivity. The production side of the economy is modeled as follows. 
There is a representative firm producing homogeneous final goods by combining various intermediate goods indexed by $s$ :

$$
Y=\Pi_{s=1}^{S} Y_{s}^{\theta_{s}}, \text { where } \sum_{s=1}^{S} \theta_{s}=1
$$

The $S$ intermediate goods are produced by as many industries. In a given intermediate good industry $s$, there are $M_{s}$ establishments that produce differentiated goods as monopolistic competitors. These products from these establishments are combined by a constant elasticity of substitution aggregator and become the industry's intermediate good output $Y_{s}$ :

$$
Y_{s}=\left(\sum_{i=1}^{M_{s}} Y_{s i}^{\frac{\sigma-1}{\sigma}}\right)^{\frac{\sigma}{\sigma-1}},
$$

where $Y_{s i}$ is the output of firm $i$ in industry $s$ and $\sigma$ is the elasticity of substitution. For the problem to be well defined, $\sigma$ is assumed to be greater than 1. Finally, a firm's output $Y_{s i}$ is produced by a technology with constant returns to scale in capital and labor:

$$
Y_{s i}=A_{s i} K_{s i}^{\alpha_{s}} L_{s i}^{1-\alpha_{s}}
$$

where $A_{s i}$ is the firm's physical productivity, commonly denoted as TFPQ, and $\alpha_{s}$ is the elasticity of output to capital. It is assumed that all establishments in a given industry have the same capital elasticity, but it may vary across industries.

The setup so far is fairly standard. Hsieh and Klenow's (2009) method differentiates itself in terms of a firm's profit maximization problem. The standard approach would write the problem as follows:

$$
\max _{L_{s i}, K_{s i}} P_{s i} Y_{s i}-w L_{s i}-R K_{s i},
$$

where the maximization over labor $\left(L_{s i}\right)$ and capital input $\left(K_{s i}\right)$ is subject to the downwardsloping demand curve derived from equation (2). It is assumed that, while a firm's product has its own price $P_{s i}$, the wage $w$ and capital rental rate $R$ are assumed to be the same for all establishments and industries in the economy. Perfectly foreseeing that the optimality conditions of the profit maximization (4) will not be satisfied by observed quantities in the plantlevel data, Hsieh and Klenow (2009) modify the problem as follows:

$$
\max _{L_{s i}, K_{s i}}\left(1-\tau_{Y s i}\right) P_{s i} Y_{s i}-w L_{s i}-\left(1+\tau_{K s i}\right) R K_{s i} .
$$

The tax-like variables $\tau_{Y s i}$ and $\tau_{K s i}$ are imputed wedges that are introduced to reconcile an establishment's observed quantities with the optimality conditions from its profit-maximization problem. These wedges will be nonzero for many reasons, including misspecification of establishments' production technology and demand system or measurement errors in the data. Hsieh and Klenow's (2009) insight was to think of these wedges as firm-specific (or idiosyncratic) distortions that stem from policies and various market failures. This interpre- 
tation naturally leads to the hypothetical question: By how much will industrial output rise when the distortions are reduced, holding fixed the industry's labor and capital use? This is their metric of the degree of misallocation in an economy.

The optimality conditions from the modified profit maximization problem lead to

$$
\begin{gathered}
1+\tau_{K s i}=\frac{\alpha_{s}}{1-\alpha_{s}} \frac{w L_{s i}}{R K_{s i}}, \\
1-\tau_{Y s i}=\frac{\sigma}{\sigma-1} \frac{w L_{s i}}{\left(1-\alpha_{s}\right) P_{s i} Y_{s i}},
\end{gathered}
$$

which show how the idiosyncratic distortions on capital $\left(\tau_{K s i}\right)$ and output $\left(\tau_{Y s i}\right)$ can be inferred from the parameter values and observed quantities on the right-hand sides.

One way to summarize the capital and output distortions is through revenue productivity (denoted as TFPR), which is a firm's TFPQ multiplied by its output price ${ }^{1}$ :

$$
T F P R_{s i} \equiv P_{s i} A_{s i}=\frac{\sigma}{1-\sigma}\left(\frac{R}{\alpha_{s}}\right)^{\alpha}\left(\frac{w}{1-\alpha_{s}}\right)^{1-\alpha_{s}} \frac{\left(1+\tau_{K s i}\right)^{\alpha_{s}}}{1-\tau_{Y s i}} .
$$

One thing of note in equation (8) is that, were it not for the idiosyncratic distortions, TFPR would be exactly the same across all the establishments in a given industry, regardless of their respective physical productivity $\left(A_{s i}\right)$. TFPR is not affected directly by TFPQ, because establishments with higher physical productivity produce more goods and sell them at a proportionately lower price. The idea is that an efficient allocation of capital and labor, undistorted by idiosyncratic distortions, is characterized by the equalization of marginal products across establishments.

From the model specification, $A_{s i}$ can be backed out from the revenue, $P_{s i} Y_{s i}$ :

$$
A_{s i}=\frac{\left(P_{s i} Y_{s i}\right)^{\frac{\sigma}{\sigma-1}}}{K_{s i}^{\alpha_{s}} L_{s i}^{1-\alpha_{s}}} \kappa_{s}, \text { where } \kappa_{s}=\frac{w^{1-\alpha}}{P_{s}}\left(P_{s} Y_{s}\right)^{\frac{1}{1-\sigma}}
$$

This formula is useful because data on establishments' output prices are not typically available. Furthermore, because we consider reducing distortions only within industries, the industryspecific term $\kappa_{s}$ can be ignored.

To derive the expression for an industry's TFP, it is useful to first determine its TFPR:

$$
\overline{\operatorname{TFPR}}_{s}=\frac{\sigma}{\sigma-1}\left(\frac{M R P K_{s}}{\alpha_{s}}\right)^{\alpha_{s}}\left(\frac{M R P L_{s}}{1-\alpha_{s}}\right)^{1-\alpha_{s}}
$$

where $M R P K$ and $M R P L$ represent the marginal revenue products of capital and labor, respectively, denoted as

$$
M R P K_{s}=R\left(\sum_{i=1}^{M_{s}} \frac{\left(1-\tau_{Y s i}\right) P_{s i} Y_{s i}}{\left(1+\tau_{K s i}\right) P_{s} Y_{s}}\right)^{-1} \text { and } M R P L_{s}=w\left(\sum_{i=1}^{M_{s}} \frac{\left(1-\tau_{Y s i}\right) P_{s i} Y_{s i}}{P_{s} Y_{s}}\right)^{-1} .
$$


The industry-level TFP for industry $s$ is

$$
T F P_{s}=\frac{Y_{s}}{K_{s}^{\alpha_{s}} L_{s}^{1-\alpha_{s}}}=\left(\sum_{i=1}^{M_{s}}\left(A_{s i} \frac{\overline{T F P R}_{s}}{T F P R_{s i}}\right)^{\sigma-1}\right)^{\frac{1}{\sigma-1}} .
$$

Without the idiosyncratic distortions, $\overline{T F P R}_{s}=T F P R_{s i}$ for all $i$, and we have

$$
T F P_{s}=\bar{A}_{s} \equiv\left(\sum_{i=1}^{M_{s}} A_{s i}^{\sigma-1}\right)^{\frac{1}{\sigma-1}} .
$$

We now have all the elements necessary to compute the ratio between the amount of final goods that will be produced with and without idiosyncratic distortions (respectively, $Y$ and $\left.Y_{\text {eff }}\right)$. We hold fixed the amount of capital $\left(K_{s}\right)$ and labor $\left(L_{s}\right)$ used in each industry:

$$
\frac{Y}{Y_{\text {eff }}}=\Pi_{s=1}^{S}\left(\frac{T F P_{s}}{\bar{A}_{s}}\right)^{\theta_{s}}=\Pi_{s=1}^{S}\left(\sum_{i=1}^{M_{s}}\left(\frac{A_{s i}}{\bar{A}_{s}} \frac{\overline{T F P R}_{s}}{T F P R_{s i}}\right)^{\sigma-1}\right)^{\frac{\theta_{s}}{\sigma-1}} .
$$

This equation is the key to our empirical analysis. More dispersion in TFPR across establishments in an industry means more dispersion in marginal products across them, which leads to lower TFP for the industry and, hence, for the economy as a whole. More importantly, equation (11) quantifies the magnitude of the output loss stemming from resource misallocation relative to the efficient allocation without within-industry TFPR dispersion.

\section{Data}

We use the Korean Mining and Manufacturing Survey provided by Statistics Korea, a restricted-access panel with data starting in 1982. Until 2007, the survey covered all mining and manufacturing establishments with five or more employees, but thereafter the cutoff was raised to 10 employees. For comparability, we consider only the 1982-2007 period. We do not exploit the panel dimension of the data in this article. The survey provides information on many variables at the establishment level, including the number of employees, value added, gross output, capital stock, investment, and so on.

We use the Korean Standard Industry Classification (KSIC, 2000) and define an industry at the four-digit level. During the sample period, the KSIC was revised four times (1984, 1992, 1998, and 2000), with the 1992 revision the most significant. We use the 2000 version (KSIC Rev. 8) as the baseline and crosswalk the classifications through each revision in reverse chronological order.

In our analysis, we drop mining establishments (the two-digit industry code 14) and consider only manufacturing industries.

\section{Parameter Values}

Following Hsieh and Klenow (2009), the capital rental rate $R$ is set to 0.1 and the elasticity of substitution between differentiated plant output to $\sigma=3$. The elasticity of output to capital 


\section{Table 1}

Evolution of Allocative Efficiency (1982-2007)

\begin{tabular}{lllllll} 
Year & 1982 & 1987 & 1992 & 1997 & 2002 & 2007 \\
\hline$Y / Y_{\text {eff }}$ & 0.55 & 0.61 & 0.62 & 0.59 & 0.57 & 0.54 \\
\hline Implied TFP gains (\%) & 81.8 & 63.9 & 61.3 & 69.5 & 75.4 & 85.2 \\
\hline Standard deviation of log TFPR & 0.68 & 0.63 & 0.61 & 0.66 & 0.67 & 0.71 \\
\hline
\end{tabular}

in each industry $\alpha_{s}$ is 1 minus its labor share in the data. The labor share is the ratio of wage payments to value added for each industry in 2005 . We multiply wage payments by a constant factor greater than 1 for all sectors to be consistent with the manufacturing labor share in the national input-output table provided by the Bank of Korea.

\section{EMPIRICAL RESULTS}

\section{Aggregate Impact of Misallocation}

We first compute the impact of resource misallocation on aggregate output. We consider industries at the four-digit level of classification and define $Y_{\text {eff }}$ as the output obtained when the TFPR of all establishments in a four-digit industry is equalized. 2 The TFPR may still differ across industries, and we reallocate capital and labor only within industries but not across them. In other words, we focus on the within-industry deviation of TFPR from the industry average. For each year, in each four-digit industry, we drop the top and bottom 1 percent of establishments to remove any TFPR outliers.

The calculated ratios of actual to efficient aggregate output from (11) are shown in the first row of Table 1. From these ratios, we calculate hypothetical TFP gains from equalizing TFPR within four-digit industries as $Y_{\text {eff }} / Y-1$, since inputs are fixed. The gains are reported in the second row. Two facts stand out. First, the estimated aggregate impact of resource misallocation within industries is very large. If the distortions are removed to equalize marginal products of establishments within industries, aggregate output and TFP will increase by more than 70 percent on average. $\underline{3}$ Second, since higher gains from efficient reallocation imply more misallocation in the actual economy, we can infer that the allocative efficiency in the Korean manufacturing sector improved from 1982 to 1992 but worsened thereafter, erasing all gains by 2007.

The third row in Table 1 is the overall dispersion measure of TFPR. To be more specific, we compute the standard deviation of log TFPR within each industry in a given year after discarding the top and bottom 1 percent of establishments. The standard deviations of log TFPR for all industries are then averaged, weighted by their value added in each year. This aggregate TFPR dispersion mirrors the allocative efficiency measure $Y / Y_{\text {eff }}$ over time: The dispersion in TFPR, which in our framework is the degree of distortion and misallocation, decreases from 1982 to 1992 but then increases. 


\section{Figure 1}

\section{Overproduction by Establishment Age $(1982,1992$, and 2007)}

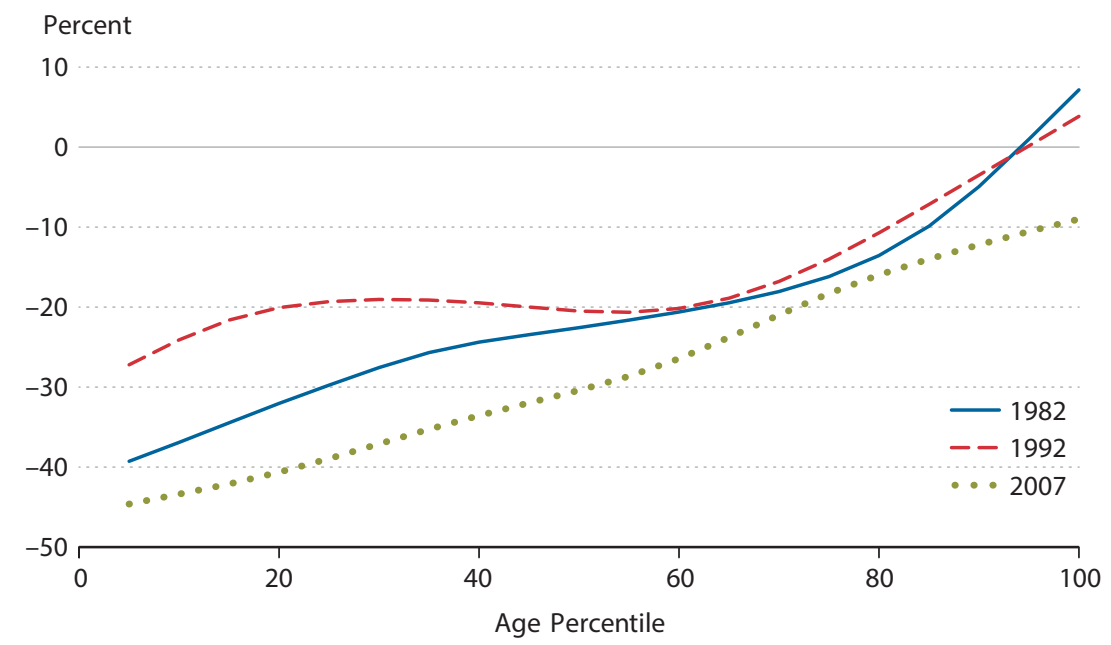

To better understand the rise and fall of the allocative efficiency of the Korean manufacturing sector over the years, we now ask how the patterns of distortions by establishment age, size, and industry change over time.

\section{Misallocation by Age and Size}

We first analyze how the idiosyncratic distortions as captured by TFPR correlate with the age of an establishment. $\underline{4}$ For this purpose, we sort establishments by age, regardless of their industry, from youngest to oldest. For each establishment, we compute how much its revenue would decrease if its TFPR were equated with the industry mean. This decrease in revenue relative to a firm's current revenue is reported as "overproduction" in Figure 1, where we show the results for only three years: the beginning of our sample (1982), the year with the best allocative efficiency (1992), and the last year of the sample (2007).. As a reference point, the efficient benchmark with no within-industry dispersion in TFPR is indicated by the flat line at zero.

One striking pattern for all three years is that an establishment's age and overproduction are positively correlated. Younger establishments (i) tend to have a higher TFPR than their respective industry average and (ii) significantly underproduce compared with the efficient benchmark. This is consistent with, for example, the interpretation that a high TFPR is a sign of financial constraints, which tend to affect younger establishments more than older ones (see, e.g., Buera, Haltiwanger, and Shin, 2011, and Foster, Haltiwanger, and Syverson, 2008).

Over the years, the three curves position themselves in a manner consistent with the aggregate results in Table 1. Between 1982 and 1992, the allocative efficiency shown in this way improved overall, with the red dashed line for 1992 closer to the zero line than the blue 
Figure 2

\section{Overproduction by Establishment Size $(1982,1992$, and 2007)}

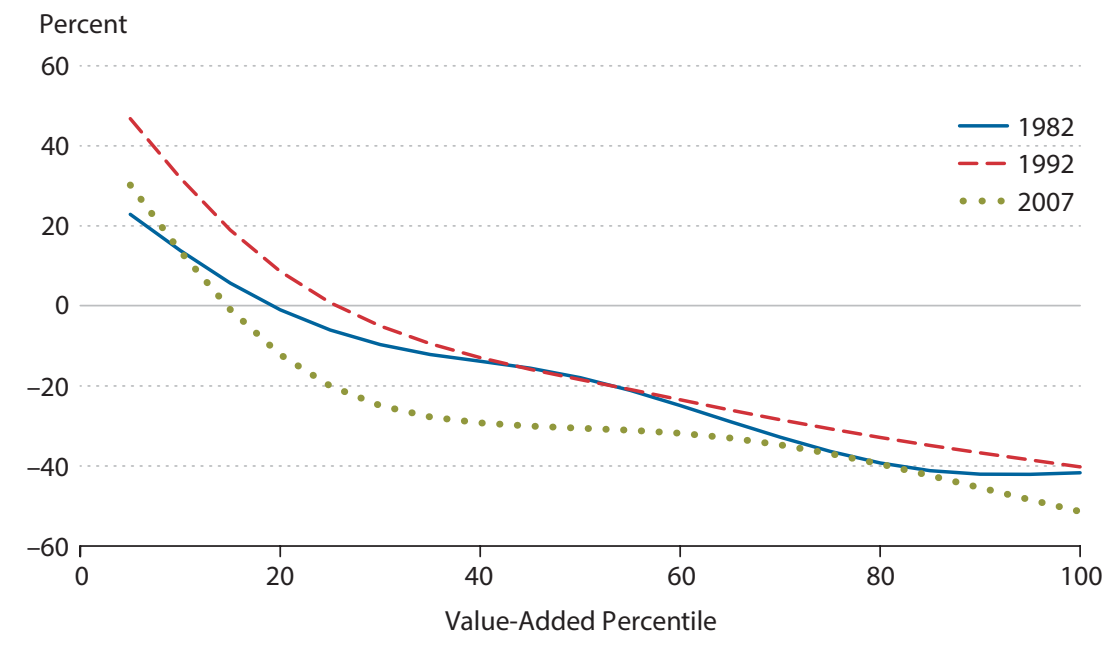

solid line for 1982. The improvement is concentrated among younger establishments. The curve then shifts outward between 1992 and 2007, mirroring the deterioration in allocative efficiency during this period.

We now explore how the TFPR of establishments correlates with their size as measured by value added. We sort establishments by value added, again regardless of their industry, from smallest to largest. For each establishment, we compute the magnitude of overproduction attributable to idiosyncratic distortions. Figure 2 shows the results for 1982, 1992, and 2007. 6 We find that small establishments tend to produce too much (i.e., a lower-than-average TFPR) and large establishments tend to produce too little (i.e., a higher-than-average TFPR) relative to the efficient benchmark.

Figure 2 shows that between 1982 and 1992, the distortions decreased for large establishments but increased for small establishments: The red dashed line is closer to the zero line for establishments in the 60th or higher percentiles, but it is farther from the zero line for those in the 20th or lower percentiles. The exact opposite pattern occurs between 1992 and 2007: The green dotted line (for 2007) is closer to the zero line than the 1992 line is for establishments in the 20th or lower percentiles, but it is farther from the zero line for those in higher percentiles.

\section{Misallocation by Age and Size Within Industries}

To determine whether a similar positive correlation between the age and overproduction of establishments exists within each industry, we repeated the exercise for each two-digit industry, holding fixed the aggregate age percentiles on the horizontal axis. In 14 of the 22 twodigit industries, we find the same or an even stronger positive relationship compared with the aggregate result in Figure 1. The other eight industries reveal relatively flat age profiles of overproduction. ${ }^{?}$ 


\section{Figure 3}

\section{Evolution of TFPR Dispersion by Two-Digit Industry}

Standard Deviation of log TFPR

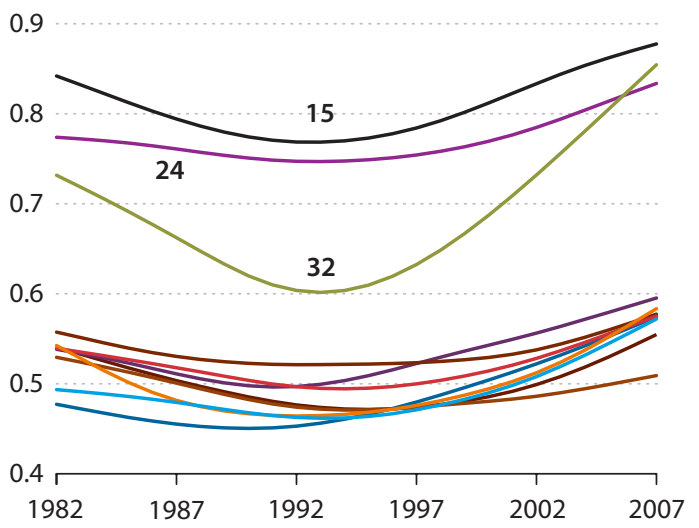

Standard Deviation of log TFPR

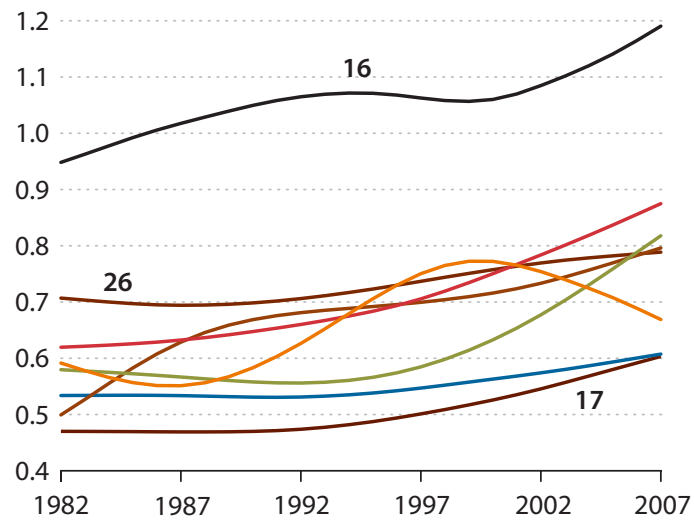

\section{Table 2}

\section{Industry Grouping by Evolution in TFPR Dispersion}

\begin{tabular}{llll} 
KSIC & $\begin{array}{l}\text { Industry description } \\
\text { (left panel of Figure 3) }\end{array}$ & KSIC & $\begin{array}{l}\text { Industry description } \\
\text { (right panel of Figure 3) }\end{array}$ \\
\hline 15 & Food, beverages & 16 & Tobacco products \\
\hline 18 & Wearing apparel; fur & 17 & Textiles \\
\hline 19 & Leather; luggage, footwear & 21 & Paper, paper products \\
\hline 20 & Wood, cork; plating materials & 26 & Non-metallic mineral products \\
\hline 24 & Chemicals, chemical products & 27 & Basic metals \\
\hline 25 & Rubber, plastics products & 30 & Office, computing machinery \\
\hline 28 & Fabricated metal products & 31 & Electrical machinery \\
\hline 29 & Machinery, equipment & 34 & Motor vehicles \\
\hline 32 & Television, communication equipment & & \\
\hline 33 & Medical, precision instruments; watches and clocks & & \\
\hline 36 & Furniture & & \\
\hline
\end{tabular}

We also analyzed the relationship between establishment size (i.e., value added) and overproduction within each two-digit industry. In all 22, we found strikingly similar negative relationships between establishment size and overproduction, which aggregate directly to the overall pattern shown in Figure 2.

The within-industry age and size profiles of overproduction also tend to shift over the sample period in a manner consistent with the shifts in the aggregate age and size profiles. In three industries $(31,32$, and 34$)$, we observe a particularly sharp worsening of distortions 
(underproduction) for young and small establishments in the second half of the sample period. These three industries are an important part of the Korean manufacturing sector, accounting for 31 percent of total value added as of 2007.

\section{Misallocation by Industry}

We now ask whether TFPR dispersion evolves in different patterns across industries. For this purpose, we start with the standard deviations of $\log$ TFPR within four-digit industries and aggregate them up to the two-digit level, weighting by value added shares in each year. We then use smoothing splines with a smooth factor of 0.01 to construct the time series for each two-digit industry.

Of the 22 two-digit industries, 19 fall into one of two groups: those whose TFPR dispersion tracks the aggregate series and exhibits a $\mathrm{U}$-shape over the years or those whose TFPR dispersion increases more or less over the entire sample period. 8

The left panel of Figure 3 plots the time series of the log TFPR standard deviation for the 11 industries in the $U$-shape group. With the exceptions of industries 15,24, and 32, all industries in this group have very similar time series. The right panel shows the eight industries whose TFPR dispersion increases through the years. Their patterns are more heterogeneous and most of the increase over time occurs after 1992, the peak year in terms of allocative efficiency in the aggregate series.

Table 2 lists the industries that appear in the left (i.e., U-shape over time) and right (i.e., increasing over time) panels of Figure 3. We tried to uncover industry-level observable characteristics that correlate with these two distinct patterns. The only significant finding is that the industries in the right panel, on average, have a higher capital intensity and HerfindahlHirschman index than those in the left panel.

The aggregate TFPR dispersion reported in Table 1 is an average across the 22 two-digit industries weighted by their value added shares. Over the sample period, we find that the value added shares of the two groups are stable. The value added share of the industries in the left panel as a whole starts at 49 percent of the entire manufacturing sector in 1982 and rises to 52 percent by 1992 and then remains more or less flat thereafter. The value added share of the second group, on the other hand, decreases from 43 percent to 40 percent between 1982 and 1992 but then hovers around 40 percent for the next 15 years. We conclude that, at this level of disaggregation, the aggregate TFPR dispersion reflects the dynamics of the industrylevel TFPR dispersion rather than shifting weights across industries. $\underline{9}$

\section{INTERPRETING THE OBSERVED PATTERN OF ALLOCATIVE EFFICIENCY}

One interesting observation is that the rise and fall of allocative efficiency are broadly consistent with the shifts in the overall economic policy in Korea during the sample period. As described in Buera and Shin (2009) and Sakong and Koh (2010), beginning in 1982, a largescale economic reform was implemented to undo the heavy and chemical industry promotion of the 1970s. The government ceased directed subsidy programs and aided the "rationaliza- 
tion" of these industries through mergers and acquisitions. It is in no way a proof, but the aggregate measure of distortions is consistent with the pivot in policy orientation in 1982.

In 1993, a new administration introduced economic policies emphasizing deregulation. The prevailing assessment is that, because the economy at that time was dominated by a handful of large business groups, the deregulation ended up amplifying their market powers, rather than achieving more efficiency through competition. This view is consistent with the observed decline in allocative efficiency since 1992. The economic policies following the 1997 Asian financial crisis through 2007 are more difficult to describe with such broad strokes, especially with regard to policies that could directly affect allocative efficiency.

\section{CONCLUDING REMARKS}

Using detailed micro-level production-side analyses to address the important question of cross-country TFP differences, Hsieh and Klenow (2009) has had-and continues to have-a large impact on the field of economic growth and development. At the same time, many researchers raised concerns about interpreting the TFPR dispersion as misallocation resulting from distortions that affect plants differentially. The most common refrain is that model misspecification and even classical measurement errors will show up as TFPR dispersion, which is a very valid criticism.

In this article, we give due consideration to the method of Hsieh and Klenow (2009) and use it as a diagnostic test of the allocative efficiency for the Korean manufacturing sector over a quarter century. We find non-monotonic dynamics of aggregate distortion measures, which largely reflect similar dynamics of many two-digit industries. The establishment-level distortion measures systematically correlate with age and value added throughout the sample period, and these relationships also evolve in a manner consistent with the aggregate TFPR dispersion.

Our analysis is not meant to be evidence of the dispersion-as-misallocation theory. However, the clear and coherent patterns across industries and across time suggest that such dispersion should not be dismissed as misspecification or measurement errors: The question is then why misspecification or measurement errors can exhibit such distinct patterns across industries and time.

A promising avenue for future research is to analyze how economic policies, production technology, and competitive market environments changed at the industry level over time and determine how such changes correlate with the dispersion measures. 


\section{Kim, Oh, Shin}

\section{NOTES}

1 The distinction between TFPQ and TFPR (and the notation) comes from Foster, Haltiwanger, and Syverson (2008).

$\underline{2}$ We equate a firm in the model with an establishment in the data, which may not be an innocuous assumption.

3 Hsieh and Klenow (2009) present the TFP gains from efficient reallocation for China, India, and the United States in their Table 4. Consistent with the four countries' relative ranking in terms of economic development, the calculated TFP gain for Korea is larger than that for the United States but smaller than that for China and India.

4 An establishment's age is the difference between the survey year and its reported birth year.

$\underline{5}$ The curves are constructed by smoothing splines with a smooth factor of 0.001 .

6 We again use smoothing splines with a smooth factor of 0.001 .

$\underline{7}$ They are industries 20,21,24, 25, 26, 30,33, and 35. See Table 2 .

$\underline{8}$ Of the remaining three two-digit industries, industries 23 (coke, refined petroleum products, nuclear fuel) and 35 (other transport equipment) show a flat standard deviation over time. Industry 22 (publishing, printing, recorded media) has a monotonically decreasing standard deviation over time.

$\underline{9}$ To be more precise, we also computed the aggregate TFPR dispersion holding constant each four-digit industry's value-added share at its mean over the sample period. The resulting aggregate TFPR dispersion measures look very similar to those shown in Table 1, except for the first eight years. About half of the initial decline in TFPR dispersion reflects the shifting weights from the second to the first group, since the second group on average has a slightly higher standard deviation of log TFPR.

\section{REFERENCES}

Abramovitz, Moses. "Resource and Output Model in the United States Since 1870." American Economic Review, May 1956, 46(2), pp. 6-11; http://www.jstor.org/stable/1910656?seq=7\#page scan tab contents.

Buera, Francisco, J.; Kaboski, Joseph P. and Shin, Yongseok. "Finance and Development: A Tale of Two Sectors." American Economic Review, August 2011, 101(5), pp. 1964-2002; https://doi.org/10.1257/aer.101.5.1964.

Buera, Francisco J. and Shin, Yongseok. "Productivity Growth and Capital Flows: The Dynamics of Reforms." NBER Working Paper No. 15268, National Bureau of Economic Research, August 2009; http://www.nber.org/papers/w15268.pdf.

Foster, Lucia; Haltiwanger, John and Syverson, Chad. "Reallocation, Firm Turnover, and Efficiency: Selection on Productivity or Profitability?" American Economic Review, March 2008, 98(1), pp. 39-425; https://doi.org/10.1257/aer.98.1.394.

Hsieh, Chang-Tai and Klenow, Peter J. "Misallocation and Manufacturing TFP in China and India." Quarterly Journal of Economics, November 2009, 124(4), pp. 1403-448; https://doi.org/10.1162/qjec.2009.124.4.1403.

Korean Standard Industry Classification. 2000 version, KSIC Rev. 8; http://www.kostat.go.kr/portal/english/help/1/index.board?bmode=download\&bSeq=\&aSeq=59908\&ord=1.

Parente, Stephen L. and Prescott, Edward C. Barriers to Riches. Cambridge, MA: MIT Press, 2000.

Sakong, II and Koh, Youngsun. "The Korean Economy: Six Decades of Growth and Development." Sejong-si, Korea: Korea Development Institute, 2010. In Korean. 